\title{
Effects of exercising before versus after eating on dieting and exercise evaluations: A preliminary investigation
}

\author{
Citation for published version (APA):
}

Coelho, J., Roefs, A. J., Havermans, R. C., Salvy, S-J., \& Jansen, A. (2011). Effects of exercising before versus after eating on dieting and exercise evaluations: A preliminary investigation. Canadian Journal of Behavioural Science-Revue Canadienne des Sciences du comportement, 43(1), 63-67. https://doi.org/10.1037/a0021736

Document status and date:

Published: 01/01/2011

DOI:

10.1037/a0021736

Document Version:

Publisher's PDF, also known as Version of record

\section{Document license:}

Taverne

Please check the document version of this publication:

- A submitted manuscript is the version of the article upon submission and before peer-review. There can be important differences between the submitted version and the official published version of record.

People interested in the research are advised to contact the author for the final version of the publication, or visit the DOI to the publisher's website.

- The final author version and the galley proof are versions of the publication after peer review.

- The final published version features the final layout of the paper including the volume, issue and page numbers.

Link to publication

\footnotetext{
General rights rights.

- You may freely distribute the URL identifying the publication in the public portal. please follow below link for the End User Agreement:

www.umlib.nl/taverne-license

Take down policy

If you believe that this document breaches copyright please contact us at:

repository@maastrichtuniversity.nl

providing details and we will investigate your claim.
}

Copyright and moral rights for the publications made accessible in the public portal are retained by the authors and/or other copyright owners and it is a condition of accessing publications that users recognise and abide by the legal requirements associated with these

- Users may download and print one copy of any publication from the public portal for the purpose of private study or research.

- You may not further distribute the material or use it for any profit-making activity or commercial gain

If the publication is distributed under the terms of Article $25 \mathrm{fa}$ of the Dutch Copyright Act, indicated by the "Taverne" license above, 


\title{
Effects of Exercising Before Versus After Eating on Dieting and Exercise Evaluations: A Preliminary Investigation
}

\author{
Jennifer Coelho \\ University of Savoie
}

Sarah-Jeanne Salvy

State University of New York at Buffalo

\author{
Anne Roefs and Remco Havermans \\ Maastricht University
}

\author{
Anita Jansen \\ Maastricht University
}

\begin{abstract}
Psychological processes may play a role in the evaluation of the effectiveness of exercise and subsequent food intake. In order to further investigate this phenomenon, the effects of the timing of exercise relative to an eating opportunity were evaluated. Female undergraduate participants who were of average weight and did not exercise regularly were randomly assigned to one of three conditions (exercise before eating $[n=10]$, exercise after eating $[n=11]$, or no exercise $[n=12]$ ). Expectations of the effectiveness of the exercise, value of dieting, and intake were assessed. Participants who exercised after eating had higher expectations of the effectiveness of the exercise than those who exercised before eating, while those who exercised before eating reported valuing dieting more than controls. No effects on intake emerged; therefore, there appears to be a disconnect between dieting appraisals and actual eating behaviour. The results are discussed in relation to theories on conflicting goals.
\end{abstract}

Keywords: exercise, expectations, food intake, health beliefs, value of dieting

Individuals who are trying to lose weight are encouraged to expend more calories than they ingest; however, psychological processes may interfere with accurate appraisal of caloric expenditure. This, in turn, may account for difficulties in evaluating when energy balance has been reached, and make long-term weight loss difficult. Individuals overestimate how much progress they will make during exercise toward improving their fitness, and these overoptimistic expectations make them more susceptible to subsequent temptations (Fishbach \& Dhar, 2005). More specifically, individuals who are about to begin a workout report higher expectations of how effective this workout will be toward their fitness than individuals who have just completed a workout. Furthermore, individuals who are about to begin a workout express more intentions to eat a high-caloric meal than do individuals who have just completed a workout (Fishbach \& Dhar, 2005). These overly optimistic expectations about future progress toward exer-

Jennifer Coelho, Department of Psychology, University of Savoie; Anne Roefs, Remco Havermans, and Anita Jansen, Department of Clinical Psychological Science, Maastricht University; and Sarah-Jeanne Salvy, Department of Pediatrics, State University of New York at Buffalo.

This research was supported by a grant from the Canadian Institutes of Health Research awarded to J. S. Coelho. The authors gratefully acknowledge the assistance of Joke Demandt and Loes Peeters for their help with participant recruitment and data collection. Portions of this research were presented at the Annual Convention of the Eating Disorders Research Society, September 2008, Montreal, Canada.

Correspondence concerning this article should be addressed to Jennifer Coelho, Department of Psychology, University of Savoie, Jacob Bellecombette BP 1104, 73011 Chambéry cedex France. E-mail: jennifer.coelho@ univ-savoie.fr cise goals can be counterproductive toward weight-loss, if they lead individuals to eat high-caloric foods.

The compensatory health beliefs model (Rabiau, Knäuper \& Miquelon, 2006) provides a framework which can account for the effects of borrowing from future goal progress (Fishbach \& Dhar, 2005). According to this model, individuals make plans to compensate for indulgence in temptations. For example, compensatory thoughts and intentions are generated by weight-concerned individuals upon exposure to temptation to reduce the conflict between eating high-caloric foods and maintaining a slim figure. In line with this model, the participants in the Fishbach and Dhar study reported more intentions to eat a high-caloric meal before exercise. According to Rabiau and colleagues, compensatory beliefs will be more prevalent when individuals are primed with temptation (therefore, seeing cookies before exercising will lead to more prevalent compensatory beliefs). In contrast, priming the means to achieving a healthy goal activates behaviour consistent with this goal (Shah \& Kruglanski, 2003); therefore, we might expect individuals who are primed with exercising will be more likely to eat healthily. Fishbach and Dhar also assert the importance of timing of exercise relative to temptation (e.g., high-caloric food). Namely, individuals are more likely to borrow from future progress than to act on actual progress because anticipation of future progress leads to biased, overly optimistic expectations, which in turn makes acting on incongruent goals more likely. Therefore, we expect that exposure to an eating opportunity would lead to increased intake (and a reduced value of dieting) only for those who have an upcoming occasion to exercise, and not those who have recently exercised (for whom the value of dieting and healthy eating should be activated). In other words, the timing of exercise relative to eating is important because those who have an upcoming exercise session are more likely to 
overestimate the progress that they will make to their goal (and be more likely to indulge) than those who complete exercise prior to an eating opportunity.

The current study was designed to further investigate the nature of the timing of exercise relative to an eating opportunity. There are some limitations to the study conducted by Fishbach and Dhar (2005), including the fact that they measured behavioural intentions (not food intake), and lacked a no-exercise control group. We predicted that those who were exposed to food temptations (as part of a taste test) prior to exercising would eat more and value dieting less than controls and those who exercised before eating. It was further expected that those who exercised after eating would have higher expectations of the upcoming exercise than those who exercised before eating. This hypothesis was based on the compensatory health beliefs model, which predicts that cognitive dissonance and a state of discomfort arises when confronted with temptation, and that compensatory beliefs are generated to alleviate this discomfort (Rabiau et al., 2006).

\section{Method}

\section{Participants}

Female undergraduates $(n=56)$ were recruited from the Faculties of Psychology and Health, Medicine, and Life Sciences. Females were selectively recruited given that the majority of women wish to lose weight (even when average weight), whereas males are split between wishing to lose versus maintain/gain weight (Neighbors \& Sobal, 2007). Participants could choose either course credit or a cash voucher as compensation (€7.50 was offered to control participants, who attended only the taste test, while $€ 12.50$ was offered to those assigned to an exercise group, who attended both the exercise and taste test). Participants who did not engage in regular exercise (i.e., a maximum of once weekly) were selectively recruited to maximize the probability that they would view the exercise as contributing toward their fitness. Participants were excluded from final analyses if they were outside the average weight range (i.e., a body mass index [BMI] which was not between 18.5 and $25 ; n=16^{1}$ ) or if they did not follow the experimenter's instructions $(n=1)$. Participants who reported awareness that their food intake was being measured were also excluded $(n=9)$, given that knowledge of monitoring of food intake may alter eating behaviour (e.g., Herman, Polivy \& Silver, 1979). Three participants were both outside of the average weight range and suspicious that their intake was being measured. The final sample consisted of 33 females.

\section{Measures}

Expectations and evaluation of exercise. Prior to exercising, women rated the extent to which their upcoming workout would help them toward becoming fit/in shape. This question was embedded among four filler questions (academic/social expectations). Participants also rated their expectations of the difficulty of the upcoming workout. After completing the exercise, individuals evaluated the extent to which their exercise session helped them toward improving/maintaining their fitness. All ratings were completed on a scale of 1 (not at all) to 10 (completely).
Value of dieting and exercise. Participants rated the extent to which they valued: losing weight, dieting, devoting efforts to eating less, maintaining a diet while others around them are eating unhealthy food, thinness, and avoiding urges to eat unhealthy foods (as in Coelho, Polivy, Herman \& Pliner, 2008). Participants rated each question on a scale of 1 to 10 , and items were summed to create a total score, with higher scores representing a higher value of dieting (possible range $=6-60$ ). Cronbach's alpha was .87 (95\% confidence interval [.781-.927]). Participants also rated the extent to which they valued being fit (on a scale of 1 to 10).

\section{Procedure}

Participants were recruited for a study purportedly investigating the effects of exercise on taste perception. During scheduling, participants were asked to eat breakfast 3 hours prior to the taste test, and then to refrain from eating again until after the taste test. The experimenter also provided participants with instructions regarding their experimental session, depending on the condition to which they had been randomly assigned.

Exercise before eating $(\boldsymbol{n}=10)$. Participants were asked to participate in a 30-minute exercise session (between the hours of 10:00 a.m. and 11:30 a.m.), and to return to the lab two hours after the exercise to participate in a taste test (between 12:30 p.m. and 2:00 p.m.). A two-hour window between the exercise and taste test was chosen as exercise can induce nausea, which dissipates within 90 minutes (Kondo et al., 2001). Exercise consisted of 30 minutes of jogging on a treadmill (SportsArt Fitness TR33, Taiwan), with the speed of the treadmill adjusted by the experimenter to maintain the participants' heart rate around 150 beats per minute (monitored using a Polar RS400 Heart Rate Monitor, Finland).

Exercise after eating $(\boldsymbol{n}=\mathbf{1 1})$. Participants arrived at the laboratory between 12:30 p.m. and 2:00 p.m., rated their expectations of the upcoming workout, and then completed the taste test. Participants returned to the lab two hours later (between 2:30 p.m. and 4:00 p.m.) to complete the exercise (30 minutes on a treadmill). Upon completion of the exercise, participants evaluated their workout.

Control $(n=12)$. Participants were asked not to exercise on the day of the experiment, and arrived at the lab between 12:30 p.m. and 2:00 p.m. to complete the taste test.

Upon arrival, all participants completed an informed consent form and proceeded to either the taste test or exercise session (depending on their assigned condition). During the taste test, all participants were presented with heaping bowls of four foods: two "unhealthy" foods [M\&M's (484 kcal/100 $g$ ) and pepper-flavoured

\footnotetext{
${ }^{1}$ The decision to include only average-weight individuals was based on previous research that demonstrated that overweight/obese individuals were unresponsive to acute manipulations of exercise (Kissileff, Pi-Sunyer, Segal, Meltzer \& Foelsch, 1990). The pattern of results was similar for dieting-related goals when including all participants; however, the group differences in expectations of exercise disappeared, supporting the assertions of Kissileff and colleagues that average-weight individuals are more responsive to acute exercise manipulations. Including only average-weight females is common in research on the effects of an acute exercise session on food intake (e.g, Hubert, King \& Blundell, 1998; Maraki et al., 2005). Five of the 16 participants who were excluded for being outside of the average-weight range were underweight $(\mathrm{BMI}<18.5)$.
} 
potato chips $(528 \mathrm{kcal} / 100 \mathrm{~g})$ ] and two "healthy" foods [raisins (299 kcal/100 $g$ ) and banana slices $(95 \mathrm{kcal} / 100 \mathrm{~g})]$. The experimenter asked participants to rate each food on a variety of dimensions (e.g., sweetness, crunchiness), and informed them that they had 10 minutes to complete the task. The experimenter surreptitiously weighed each of the foods to measure consumption and converted this into caloric intake (based on the food's caloric density).

After completing the taste test, participants were asked to describe the purpose of the study, with those who suspected that their intake was being measured excluded from analyses. Participants then completed the Value of Dieting and Exercise Questionnaire. Finally, the experimenter probed participants about their compliance with the eating instructions, and measured their height and weight. Participants were debriefed upon the conclusion of the study. All procedures were approved by the Psychology Ethics Committee at Maastricht University.

\section{Results}

Analyses were conducted using SPSS for Windows (version 15.0.1). All reported effect sizes are partial eta squared.

\section{Participant Characteristics}

Participants were between the ages of 18 and $42(M=20.8$, $S D=4.1)$, with a mean BMI of $21.7(S D=1.4)$. No significant differences across groups existed for either age, $F(2,30)=0.936$, $p>.05, \eta_{\mathrm{p}}^{2}=.059$, or BMI, $F(2,30)=0.789, p>.05, \eta_{\mathrm{p}}^{2}=.050$. All participants reported valuing fitness to at least a moderate extent, with a mean reported value of $7.3(S D=1.5$; range $=$ 4-10).

\section{Expectations and Evaluation of Exercise}

Analysis of variances (ANOVAs) were conducted on participants' ratings of their expectations of the upcoming exercise, and evaluations of the exercise. This analysis was limited to individuals in the exercise conditions ${ }^{2}$ (those in the control condition did not complete this measure). Data were subjected to a power transform to correct for a violation of homogeneity of variance. In line with the a priori hypothesis, individuals who exercised after eating reported higher expectations that their upcoming workout would contribute to becoming fit than those who exercised before eating, $F(1,19)=5.055, p \leq .05, \eta_{\mathrm{p}}^{2}=.210$. However, the results of the ANOVA on participants' evaluation of exercise demonstrated that there were no statistically significant differences between the participants who exercised before eating and those who exercised after eating in their evaluation of how much the exercise session contributed to their overall fitness, $F(1,19)=1.32, p>$ $.05, \eta_{\mathrm{p}}^{2}=.065$. See Table 1 for raw mean values. No differences emerged across the two exercise groups in their expectations about the difficulty of the upcoming exercise session, $t(10.45)=0.158$, $p>.05$.

\section{Value of Dieting}

ANOVA demonstrated a statistically significant effect of condition on ratings of the importance of dieting, $F(2,29)=4.26, p \leq$ $.05, \eta_{\mathrm{p}}^{2}=.227$. Tukey's post hoc tests demonstrated that individ-
Table 1

Means (and Standard Deviations) for Dependent Variables Across the Three Experimental Conditions

\begin{tabular}{lccc}
\hline Control, & $\begin{array}{c}\text { Exercise before } \\
\text { eating, } \\
n=10\end{array}$ & $\begin{array}{c}\text { Exercise after } \\
\text { eating, } \\
n=11\end{array}$ \\
\hline $\begin{array}{l}\text { Dependent variables } \\
\text { Expectations of exercise }\end{array}$ & - & $5.1(2.5)^{\mathrm{a}}$ & $7.0(0.9)^{\mathrm{b}}$ \\
Evaluation of exercise & - & $5.2(2.6)^{\mathrm{a}}$ & $6.4(1.4)^{\mathrm{a}}$ \\
Value of dieting & $24.4(9.9)^{\mathrm{a}}$ & $36.3(10.3)^{\mathrm{b}}$ & $25.9(9.9)^{\mathrm{a}, \mathrm{b}}$ \\
Food intake (kcal) & $195.1(155.3)^{\mathrm{a}}$ & $177.4(100.3)^{\mathrm{a}}$ & $185.7(104.3)^{\mathrm{a}}$ \\
\hline
\end{tabular}

Note. Differences in mean values for a variable that reached statistical significance $(p \leq .05)$ are denoted by different superscript letters.

uals who exercised before eating reported valuing dieting more than did the no-exercise controls (see Table 1); however, the difference between the value of dieting reported by those who exercise before eating and those who exercised after eating did not reach traditional levels of statistical significance $(p=.063)$.

\section{Food Intake}

A multivariate analysis of variance was conducted to determine whether exercise condition influenced caloric intake, with total intake, and intake of healthy and unhealthy food entered as dependent variables. There were no statistically significant effects of condition on these measures, Wilk's $\lambda=0.92, F(4,58)=0.63$, $p>.05, \eta_{\mathrm{p}}^{2}=.042$, and no statistically significant effects of condition emerged on total caloric intake, $F(2,30)=0.06, p>$ $.05, \eta_{\mathrm{p}}^{2}=.004$, nor on intake of specifically unhealthy foods, $F(2$, $30)=0.125, p>.05, \eta_{\mathrm{p}}^{2}=.008$, or healthy foods, $F(2,30)=$ 1.02, $p>.05, \eta_{\mathrm{p}}^{2}=.064$; see Table 1 .

\section{Discussion}

The current study examined women's value of dieting, exercise expectations, and food intake as a function of whether eating preceded or followed exercise. As expected, individuals who exercised after eating had higher expectations about their upcoming

\footnotetext{
${ }^{2}$ While these data were amenable to a repeated measures analysis, the hypotheses predicted a between-subjects effect, rather than a withinsubjects effect. According to Fishbach and Dhar (2005), plans to pursue an activity lead individuals to overestimate the progress that will be made towards their goals (and subsequent indulgence in conflicting goals) Cognitive dissonance and generation of compensatory health beliefs (Rabiau et al., 2006) could play a role in any (lack of) change in expectations within subjects. More specifically, those individuals who exercised after eating may have generated compensatory health beliefs to allay any conflict that was generated between short-term goals to enjoy the highcaloric food and longer-term goals to achieve/maintain fitness and a healthy weight. These beliefs may be inaccurate, yet individuals are unlikely to evaluate the accuracy of these beliefs (see Rabiau et al., 2006, p. 141). We would therefore not expect to see accurate reappraisals of the effectiveness of exercise within individuals, if the original evaluation of the expectation was based on an inaccurate compensatory belief. We can, however, compare the expectations and evaluations of exercise across groups, and make inferences based on any differences. Therefore, we were primarily interested in the differences between (but not within) the exercise before eating versus the exercise after eating groups.
} 
exercise than individuals who exercised before eating. Individuals who exercised after eating may have bolstered their expectations about the effectiveness of their upcoming exercise to make themselves feel better about the fact that they were about to eat snack foods. This is in line with the compensatory health beliefs model (Rabiau et al., 2006), and suggests that the timing of eating relative to exercise may influence health behaviours.

Individuals who exercised before eating accorded a higher value to dieting than the others (statistically significantly higher levels than controls, though the differences with individuals who exercised after eating did not reach statistical significance). This fits with the prediction that their value of healthy behaviour (e.g., dieting and weight loss) would be primed by their participation in behaviour consistent with that goal (i.e., an exercise session; Shah \& Kruglanski, 2003). However, although individuals who exercised before eating reported a higher value of dieting, this selfreported measure did not map onto actual behaviour.

The fact that there were no differences in intake across conditions does not fit with the self-reported intentions obtained by Fishbach and Dhar (2005). While the food intake analysis could be limited by the small sample size, inspection of the means demonstrates that there were no tendencies for one group to eat differentially. Similarly, the use of the taste test paradigm may have attenuated consumption, as individuals were only required to taste a small sample to complete the ratings but could eat as much as they wanted (leading to large standard deviations, which can make it difficult to detect differences across groups). However, it is unlikely that the use of this paradigm prevented detection of differences, as it has been used successfully in previous studies and individuals have consumed relatively large amounts during taste tests, even when satiated (e.g., Knight \& Boland, 1989). Furthermore, the lack of effect of exercise on intake in the current study is consistent with previous studies (Harris \& George, 2008; Maraki et al., 2005). Therefore, it may be prudent to view self-reported dieting and eating intentions with caution, as these self-reports may not map onto behaviour. A meta-analysis indicated that large increases in intentions produce only small-to-medium changes in actual behaviour (Webb \& Sheeran, 2006), emphasising the importance of measuring eating behaviour as opposed to merely behavioural intentions.

This study is limited by small sample size and the use of single-item measures that may have limited validity and reliability. The single-item questions were adapted from those used by Fishbach and Dhar (2005), and were employed in order to facilitate the ease of interpreting the meaning of the results. The utility of single-item measures has been defended (Bowling, 2005); however, future researchers may wish to employ multi-item assessment techniques to assess the potential different dimensions associated with exercise expectations and evaluation. Another limitation is the exclusion of regular exercisers and overweight individuals. Regular exercisers were excluded as it was feared that these individuals would not perceive an acute 30-minute workout as contributing significantly to their overall fitness. Overweight individuals were also excluded from analyses, as the pattern of results changed for the exercise expectations. Research has indicated that overweight women perceive higher levels of exertion and report more displeasure during exercise than do normal-weight women (Ekkekakis \& Lind, 2006).
Overweight women may be particularly likely to have conflicting goal systems (i.e., value both weight loss and consumption of palatable food); therefore, future research investigating the effects of weight status on dieting/exercise evaluations could provide insight into the compensatory health beliefs model. It could also be fruitful to investigate whether the type of exercise influences individuals' expectations and subsequent dieting/eating behaviour, as the intensity or the nature of the exercise (e.g., team vs. individual) may also play a role in the extent to which (over)estimation of progress toward fitness goals occurs. Similarly, investigation of the role of participants' knowledge about diet and exercise could provide insight into the generalisability of the results. While it is possible that knowledge about caloric expenditure during exercise may prevent biased estimations, researchers have shown that even nutrition experts are susceptible to certain intake biases (e.g., Wansink, van Ittersum \& Painter, 2006). As the current research suggests that the timing of exercising may influence the value of dieting, further investigation in this area is warranted in order to elucidate factors that may ultimately aid weight-loss.

\section{Résumé}

Les processus psychologiques pourraient influencer l'évaluation de l'efficacité de l'exercice et la consommation de nourriture subséquente. Afin d'étudier ce phénomène plus en détails, l'effet du moment de la période d'exercice par rapport au moment de consommation de nourriture a été évalué. Des femmes de premier cycle universitaire de taille et poids moyens n'effectuant pas d'exercices régulièrement ont été réparties aléatoirement dans trois conditions (exercice avant le repas $[n=10]$, exercice après le repas $[n=11]$ ou pas d'exercice). Les attentes quant à l'efficacité de l'exercice, l'importance accordée à la diète ainsi que la consommation de nourriture ont été mesurées. Les participantes qui s'exerçaient après le repas avaient des attentes plus élevées quant à l'efficacité de l'exercice que celles s'exerçant avant le repas, alors que celles s'exerçant avant le repas accordaient plus d'importance à la diète que les contrôles. Aucun effet sur la consommation n'a émergé; ainsi, il semble y avoir une discordance entre les attitudes face à la diète et le comportement alimentaire réel. Les résultats sont discutés à la lumière des théories sur les buts contradictoires.

Mots-clés : exercice, attentes, consommation de nourriture, croyances sur la santé, importance de la diète

\section{References}

Bowling, A. (2005). Just one question: If one question works, why ask several? Journal of Epidemiology and Community Health, 59, 342-345.

Coelho, J. S., Polivy, J., Herman, C. P., \& Pliner, P. (2008). Effects of food-cue exposure on dieting-related goals: A limitation to counteractive-control theory. Appetite, 51, 347-349.

Ekkekakis, P., \& Lind, E. (2006). Exercise does not feel the same when you are overweight: The impact of self-selected and imposed intensity on affect and exertion. International Journal of Obesity, 30, 652-660.

Fishbach, A., \& Dhar, R. (2005). Goals as excuses or guides: The liberating effect of perceived goal progress on choice. Journal of Consumer Research, 32, 370-377.

Harris, C. L., \& George, V. A. (2008). The impact of dietary restraint and 
moderate-intensity exercise on post-exercise energy intake in sedentary males. Eating Behaviors, 9, 415-422.

Herman, C. P., Polivy, J., \& Silver, R. (1979). Effects of an observer on eating behavior: The induction of "sensible" eating. Journal of Personality, 47, 85-99.

Hubert, P., King, N. A., \& Blundell, J. E. (1998). Uncoupling the effects of energy expenditure and energy intake: Appetite response to shortterm energy deficit induced by meal omission and physical activity. Appetite, 31, 9-19.

Kissileff, H. R., Pi-Sunyer, F. X., Segal, K., Meltzer, S., \& Foelsch, P. A. (1990). Acute effects of exercise on food intake in obese and nonobese women. American Journal of Clinical Nutrition, 52, 240-245.

Knight, L. J., \& Boland, F. J. (1989). Restrained eating: An experimental disentaglement of the disinhibiting variables of perceived calories and food type. Journal of Abnormal Psychology, 98, 412-420.

Kondo, T., Nakae, Y., Mitsui, T., Kagaya, M., Matsutani, Y., Horibe, H., et al. (2001). Exercise-induced nausea is exaggerated by eating. Appetite, 36, 119-125.

Maraki, M., Tsofliou, F., Pitsiladis, Y. P., Malkova, D., Mutrie, N., \& Higgins, S. (2005). Acute effects of a single exercise class on appetite, energy intake and mood: Is there a time of day effect? Appetite, 45, 272-278.
Neighbors, L. A., \& Sobal, J. (2007). Prevalence and magnitude of body weight and shape dissatisfaction among university students. Eating Behaviors, 8, 429-439.

Rabiau, M., Knäuper, B., \& Miquelon, P. (2006). The eternal quest for optimal balance between maximizing pleasure and minimizing harm: The compensatory health beliefs model. British Journal of Health Psychology, 11, 139-153.

Shah, J. Y., \& Kruglanski, A. W. (2003). When opportunity knocks: Bottom-up priming of goals by means and its effects on self-regulation. Journal of Personality and Social Psychology, 84, 1109-1122.

Wansink, B., van Ittersum, K., \& Painter, J. E. (2006). Ice cream illusions: Bowls, spoons, and self-served portion sizes. American Journal of Preventive Medicine, 31, 240-243.

Webb, T. L., \& Sheeran, P. (2006). Does changing behavioral intentions engender behavior change? A meta-analysis of the experimental evidence. Psychological Bulletin, 132, 249-268.

Received March 4, 2010

Revision received September 21, 2010 Accepted September 22, 2010 